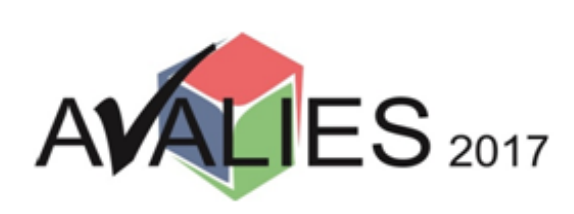

$3^{\circ}$ Simpósio Avaliação da Educação Superior

05 e 06 de setembro de 2017

Florianópolis - SC-Brasil

ISBN: 978-85-68618-04-2

\title{
O PROCESSO DE AUTOAVALIAÇÃO INSTITUCIONAL: O CASO DO COLÉGIO POLITÉCNICO DA UNIVERSIDADE FEDERAL DE SANTA MARIA
}

GUSTAVO FONTINELLI ROSSÉS

Universidade Federal de Santa Maria gustavo@politecnico.ufsm.br

ALENCAR MACHADO

Universidade Federal de Santa Maria alencar.machado@ufsm.br

\section{CRISTIANO GATTERMANN DE BARROS}

Universidade Federal de Santa Maria cristianogbarros@hotmail.com

JULIANO MOLINOS DE ANDRADE

Universidade Federal de Santa Maria juliano@politecnico.ufsm.br

\begin{abstract}
RESUMO
O objetivo geral deste estudo é "analisar os resultados da autoavaliação institucional aplicada no Colégio Politécnico da UFSM em 2016 a fim de identificar como os segmentos desta unidade universitária avaliaram cada dimensão abordada e quais dimensões foram melhor e/ou pior avaliadas pelos sujeitos pesquisados". Do ponto de vista metodológico, esta é uma pesquisa do tipo quantitativa, valendo do método descrito e pela ótica de um estudo de caso, em especial o Colégio Politécnico da UFSM. Para coleta dos dados foi utilizado um questionário construído com base nas Dimensões do SINAES e aplicado a toda comunidade universitária. Para análise dos resultados utilizou-se a estatística descritiva. Como resultados identificou-se que o caso estudado está bem avaliado do ponto de vista dos participantes e ainda atende com propriedade a grande maioria dos aspectos avaliados. Como conclusão, é salutar explicitar que ao desenvolver este trabalho, intentou-se apresentar um instrumento informacional objetivo, cuja finalidade é auxiliar na busca por mecanismos que permitam a contínua melhoria de todo o planejamento dos processos de ensino e aprendizagem, no que tange ao ensino, à pesquisa e à extensão.
\end{abstract}

Palavras chave: Autoavaliação Institucional; Dimensões do SINAES; Colégio Politécnico da UFSM. 


\section{INTRODUÇÃO}

O processo de avaliação pode ser entendido como uma forma constante de se verificar o andamento de uma determinada ação. Entende-se que um processo como este se faz necessário na medida em que permite uma verificação permanente de tudo aquilo que é resultante de uma atividade. O processo de avaliação está relacionado à produção de informações sobre determinada realidade e é algo que está bastante presente no cotidiano das diversas organizações, bem como das instituições de ensino.

Segundo Davis e Grosbaum (2002) é o processo de avaliação que revela se a instituição de ensino está cumprindo o seu papel e oferecendo educação de qualidade. Tal assertiva se afirma com mais intensidade ao se tomar como referência a avaliação do ensino, levando-se em consideração suas especificidades e o atual momento de atribuição de novas diretrizes para essa finalidade.

Diante disso, para apuração do alcance dos objetivos e metas estabelecidos nas políticas públicas, mecanismos de avaliação de programas são empregados como subsídios à decisão de continuidade ou mudança de rumos, tendo em vista a necessidade de prestação de um serviço público de qualidade e boa aplicação de recursos. Com vistas a implementar a sistemática de avaliação da educação superior, em 2004, a Lei no 10.861 instituiu o Sistema Nacional de Avaliação da Educação Superior (SINAES), com o objetivo de melhorar a qualidade da educação superior no Brasil.

Com base nestes argumentos, emerge o caso da Universidade Federal de Santa Maria. A Universidade Federal de Santa Maria (UFSM), comprometida com a Avaliação Institucional, apresenta a cada ano o relatório de avaliação, dando destaque às ações desenvolvidas pela Comissão Própria de Avaliação (CPA) e Comissões Setoriais de Avaliação (CSAs), atitude imprescindível para que o processo de Avaliação Institucional ocorra de forma dinâmica e contínua. A UFSM tem hoje doze Unidades Universitárias, bem como possui três unidades de educação básica, técnica e tecnológica, sendo uma delas o Colégio Politécnico da UFSM. É nesta unidade que se optou por realizar este trabalho.

Diante disso, o objetivo geral deste estudo é "analisar os resultados da autoavaliação institucional aplicada no Colégio Politécnico da UFSM em 2016 a fim de identificar como os segmentos desta unidade universitária avaliaram cada dimensão abordada e quais dimensões foram melhor e/ou pior avaliadas pelos sujeitos pesquisados".

Justifica-se este estudo, pois ele visa fornecer informações complementares que possibilitem ao Colégio Politécnico da UFSM identificar ações a serem mantidas, revistas ou intensificadas com vistas ao alcance dos propósitos estabelecidos no seu planejamento estratégico. Além disso, outra justificativa pauta-se pela escolha do caso. Tal escolha fundamenta-se, pois os autores deste estudo são servidores do Colégio Politécnico da UFSM, bem como todos fazem parte da Comissão Setorial de Avaliação Institucional da referida Unidade de Ensino. Em consonância, a escolha deu-se pela importância e pela representatividade que o Colégio Politécnico tem para a UFSM, pois hoje oferece 01 curso de ensino médio, 11 cursos técnicos presenciais, 03 cursos técnicos na modalidade EaD, 04 cursos de graduação e 02 cursos de pós-graduação.

Por fim, como forma de facilitar a compreensão, na seção 2, são fundamentadas e descritas as questões acerca da estrutura teórica do trabalho. Nas seções 3 e 4, apresentam-se, respectivamente, os aspectos metodológicos e as análises pertinentes ao estudo de caso realizado. Por fim, a seção 5 relata as considerações do estudo. 


\section{FUNDAMENTAÇÃO TEÓRICA}

O caráter público da universidade traz o compromisso de colaborar com o desenvolvimento econômico, social e cultural da sociedade; de participar e promover, de forma dinâmica, o processo de transformação da sociedade; e de impulsionar o progresso do próprio homem, sem perder de vista os valores e a identidade cultural do meio em que está inserido. A avaliação representa um meio para que a Instituição reconheça suas potencialidades e fragilidades, auxiliando na definição das prioridades que contribuirão para seu efetivo desenvolvimento institucional.

No Brasil, o processo que instituiu a avaliação teve seu desenvolvimento a partir de quatro propostas de educação superior e de avaliação, que foram descritas nos seguintes documentos: "Programa de Avaliação da Reforma Universitária" (1983), relatório da Comissão Nacional de Reformulação da Educação Superior "Uma Nova Política para a Educação Superior Brasileira" (1985), "Relatório do Grupo Executivo para a Reformulação da Educação Superior" (1986) e o documento da Comissão Nacional de Avaliação do Ensino Superior "Programa de Avaliação Institucional das Universidades Brasileiras" (1993) (LORENTZ, et. al., 2013).

Entretanto, foi no ano de 2004 que surgiu o Sistema Nacional de Avaliação da Educação Superior (SINAES), criado pela Lei n 10.861, de 14 de abril de 2004, e formado por três modalidades: a avaliação das Instituições, dos cursos e do desempenho dos estudantes. Os resultados das avaliações possibilitam elaborar um panorama da qualidade dos cursos e Instituições de Educação Superior (IES) no País. As avaliações são coordenadas pela Comissão Nacional de Avaliação da Educação Superior (CONAES), sendo a operacionalização de responsabilidade do Instituto Nacional de Estudos e Pesquisas Educacionais Anísio Teixeira (INEP) (LORENTZ, et. al., 2013, p. 5).

Um dos objetivos essenciais do processo de Avaliação Institucional é oferecer ferramentas à administração a fim de contribuir na eficiência e na efetividade da gestão universitária. O Sistema Nacional de Avaliação da Educação Superior (SINAES) foi instituído pela Lei $\mathrm{n}^{\circ}$. 10.861, de 14 de abril de 2004 e traz a sistemática e a operacionalização do processo de Avaliação nas Instituições. A avaliação institucional é composta de três modalidades: a avaliação interna, a avaliação externa e a avaliação dos estudantes. O processo de avaliação interna, também chamado de autoavaliação, é coordenado pela Comissão Própria de Avaliação (CPA) de cada Instituição, enquanto a avaliação externa é realizada por comissões designadas pelo INEP.

\footnotetext{
A modalidade de autoavaliação institucional implica verificar a atuação da instituição em dimensões, ou indicadores, relacionados aos seguintes tópicos: Missão e plano de desenvolvimento institucional; perspectiva científica e pedagógica formadora: políticas, normas e estímulos para o ensino, a pesquisa e a extensão; responsabilidade social da IES; comunicação com a sociedade; políticas de pessoal, carreira, aperfeiçoamento, condições de trabalho; organização e gestão da instituição; infraestrutura física e recursos de apoio; planejamento e avaliação; políticas de atendimento aos estudantes e sustentabilidade financeira (REIS, SILVEIRA e FERREIRA, 2010, p. 110).
}

Para isso, toma-se com estrutura teórica deste estudo, para dar o norteamento necessário e ainda balizar a construção do instrumento de coleta de dados, as 10 dimensões do SINAES. O SINAES está fundamentado nas avaliações institucionais, de cursos e de estudantes. Tem como objetivos: 1) identificar mérito e valor das instituições, áreas, cursos e programas, nas dimensões de ensino, pesquisa, extensão, gestão e formação; 2) melhorar a 
qualidade da educação superior, orientar a expansão da oferta; 3) promover a responsabilidade social das IES, respeitando a identidade institucional e a autonomia (MEC/INEP, 2004).

A avaliação da instituição, segundo as diretrizes do SINAES, é baseada nos seguintes eixos e dimensões apresentados a seguir, na figura 1.

Figura 1 - As dez dimensões do SINAES nos cinco eixos

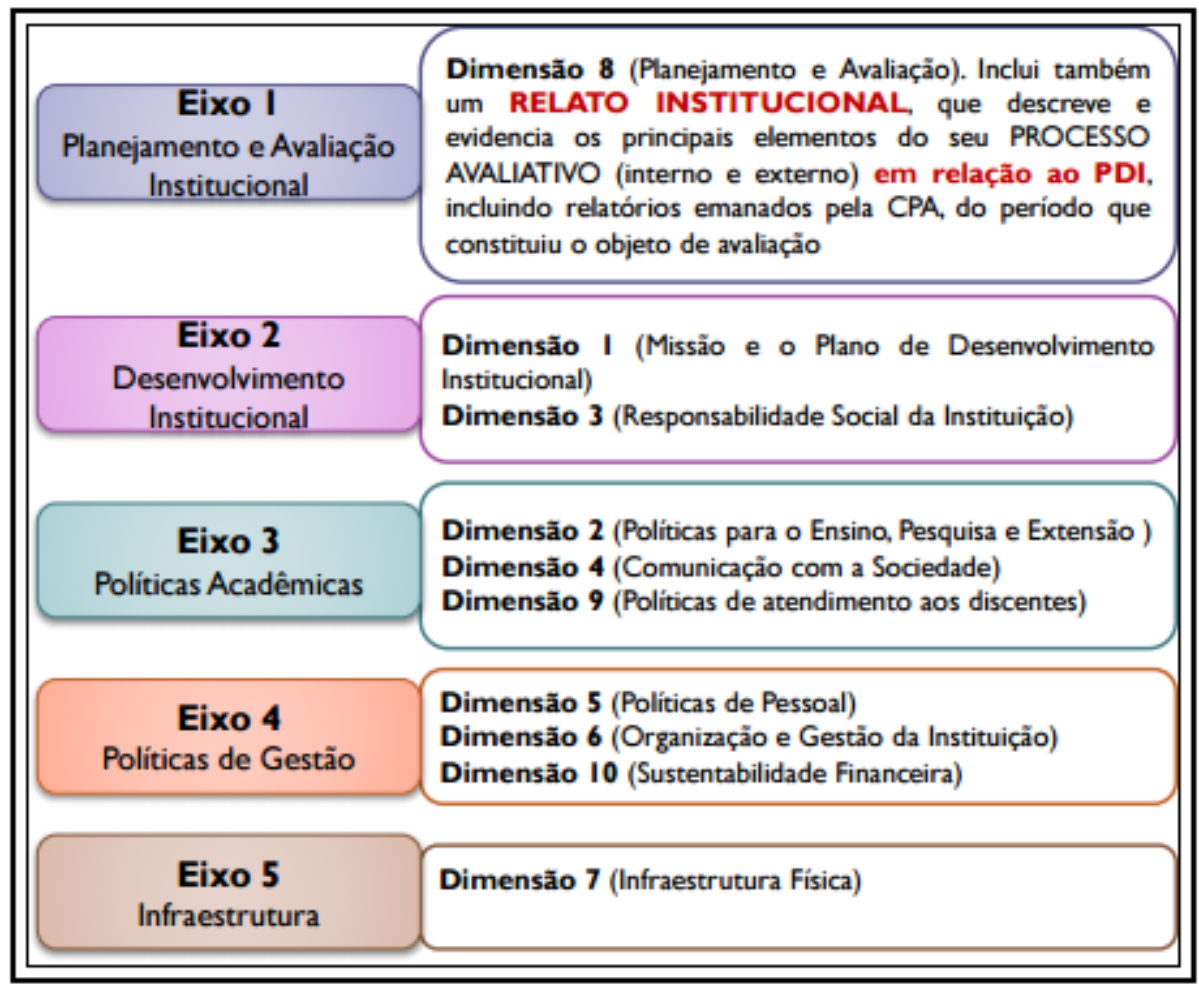

Fonte: Relatório de Avaliação Interna: Autoavaliação da UFSM 2016

Com base nestas considerações, entende-se que a avaliação interna ou autoavaliação é, portanto, um processo cíclico, criativo e renovador de análise, interpretação e síntese das dimensões que definem a instituição. Neste contexto, as informações produzidas pelas avaliações em larga escala permitem a implementação de ações mais condizentes com a oferta de uma educação de qualidade e promoção da equidade de oportunidades educacionais. Como as informações produzidas a partir de um sistema de avaliação têm papel importante sobre os rumos do sistema de ensino, além do cuidado na garantia da fidedignidade das informações oferecidas, é fundamental garantir a reflexão sobre esses resultados e constante melhoria na sua produção, seja pelo envolvimento crescente dos atores participantes do processo, seja pelo aprimoramento de métodos, instrumentos e logística de realização da avaliação.

\section{METODOLOGIA}

Do ponto de vista metodológico, este estudo se caracteriza como uma pesquisa quantitativa. Segundo Polit, Becker e Hungler (2004) a pesquisa quantitativa, que tem suas raízes no pensamento positivista lógico, tende a enfatizar o raciocínio dedutivo, as regras da lógica e os atributos mensuráveis da experiência humana. 
Além disso, o método de pesquisa adotado foi o descritivo. Conforme destaca Malhotra (2001, p. 108) "a pesquisa descritiva é um tipo de pesquisa que tem como principal objetivo a descrição de algo, normalmente características ou funções do mercado”.

O método de investigação foi o estudo de caso, que, no entendimento Gil (2009) é uma técnica de pesquisa que compreende um estudo profundo e exaustivo de um ou mais objetos, de forma que permita seu amplo e detalhado conhecimento. Para este estudo tomouse como caso o Colégio Politécnico da UFSM. O Politécnico é uma Unidade de Educação Básica, Técnica e Tecnológica da Universidade Federal de Santa Maria, prevista no Estatuto Geral da UFSM, vinculada à Coordenadoria de Educação Básica, Técnica e Tecnológica da UFSM. Tem por finalidade ministrar a Educação Básica, a Formação Inicial e Continuada, a Educação Profissional Técnica de Nível Médio e a Educação Profissional Tecnológica.

Para coleta dos dados foi utilizado um questionário direcionado aos participantes do processo de pesquisa de autoavaliação institucional. Esse questionário além de conter questões gerais aplicadas a toda comunidade, continha questões específicas para diferentes segmentos, quais sejam: gestores, docentes, técnico-administrativos em educação, discentes do ensino médio, dos cursos técnicos, dos cursos de graduação e dos cursos de pós-graduação. Para cada segmento estruturou-se um instrumento de pesquisa, cujas questões foram organizadas em cinco eixos, contemplando as dez dimensões referenciadas no marco legal do SINAES, apresentadas anteriormente na figura 1.

Ao longo deste processo de autoavaliação, foram disponibilizados sete questionários à comunidade universitária, abrangendo servidores e estudantes. O instrumento denominado "Questões Gerais" foi aplicado a todos os segmentos, visto que, trata-se de questões de interesse e entendimento comum. O referido instrumento era composto por 23 questões de múltipla escolha e 01 questão aberta por eixo. O instrumento denominado "Segmento Gestor" foi aplicado à todos os servidores que detém cargo de direção, chefia ou assessoramento. Este instrumento era composto por 10 questões de múltipla escolha e 01 questão aberta por eixo. Quanto ao instrumento denominado "Segmento Docente" foi aplicado à todos os servidores com cargos de professor do magistério superior e professor do ensino básico, técnico e tecnológico. Este instrumento era composto por 13 questões de múltipla escolha e 01 questão aberta por eixo. O instrumento denominado "Segmento Técnico-Administrativo em Educação" foi aplicado à todos os servidores com cargos técnicos. Este instrumento era composto por 11 questões de múltipla escolha e 01 questão aberta por eixo. $\mathrm{O}$ instrumento denominado "Segmento Discente de Ensino Médio e/ou Técnico" foi aplicado à todos os estudantes vinculados às escolas de ensino médio e técnico. Este instrumento era composto por 12 questões e 01 questão aberta por eixo. O instrumento denominado "Segmento Discente de Graduação" foi aplicado à todos os estudantes vinculados aos cursos de graduação da UFSM. Este instrumento era composto por 12 questões e 01 questão aberta por eixo. Por fim, o instrumento denominado "Segmento Discente de Pós-Graduação" foi aplicado à todos os estudantes vinculados aos cursos de pós-graduação. Este instrumento é composto por 12 questões e 01 questão aberta por eixo.

Quanto à operacionalização da pesquisa, o trabalho foi desenvolvido com o apoio do Centro de Processamento de Dados (CPD) da UFSM, sendo o questionário disponibilizado on line, em Sistema Interno Institucional versão web, onde o participante acessava pela internet, e respondia as questões propostas, podendo inclusive interromper o preenchimento e retomálo assim que tivesse disponibilidade. No Colégio Politécnico da UFSM, estavam habilitados a responder a avaliação um total de 1.551 participantes. Destes, 892 responderam os instrumentos de pesquisa, correspondendo a um total de $57,51 \%$. 
Findado o processo de aplicação da pesquisa, que foi de 26 de setembro a 15 de novembro de 2016, os dados puderam ser analisados. Para isso, utilizou-se como técnica a estatística descritiva. A estatística descritiva, conforme Loesch (2012) tem como finalidade resumir o conjunto de todos os dados coletados em uma dada investigação a relativamente poucos números e gráficos . Ela envolve basicamente distribuições de frequências representações tabelares e gráficas e medidas de tendência central , dispersão, dentre outros. A ideia básica é a de se estabelecer uma descrição dos dados relativos a cada uma d as variáveis, dados esses levantados através de uma amostra. Esta técnica de análise dos resultados é importante, uma vez que ela sintetiza os valores de mesma natureza e os coloca de forma organizada para uma fácil compreensão dos resultados.

Desta forma, a utilização desses instrumentos metodológicos auxiliou na compreensão de determinados aspectos que interessassem para esta situação em especial, por meio do confronto entre o idealizado e o empírico, como é o caso deste estudo.

\section{RESULTADOS}

Neste capítulo são apresentados os principais resultados obtidos ao longo da pesquisa de Autoavaliação Institucional do Colégio Politécnico da UFSM, referente ao ano de 2016. Para tanto, apresenta-se na tabela 1, os indicadores de participação por segmento, bem como se faz um comparativo da participação em relação à última aplicação da pesquisa, em 2014.

Tabela 1 - Evolução da participação na Autoavaliação Institucional 2014-2016

\begin{tabular}{|c|c|c|c|c|c|c|}
\hline \multirow{2}{*}{ SEGMENTO } & \multicolumn{3}{|c|}{2014} & \multicolumn{3}{|c|}{2016} \\
\hline & TOTAL & RESPOSTAS & $\%$ & TOTAL & RESPOSTAS & $\%$ \\
\hline Gestores & 20 & 13 & 65 & 24 & 23 & 96 \\
\hline Docentes & 82 & 55 & 67 & 93 & 76 & 82 \\
\hline Técnico-Administrativos & 37 & 15 & 40 & 34 & 31 & 91 \\
\hline Discentes Ensino Médio & 107 & 19 & 17 & 107 & 65 & 60 \\
\hline Discentes Técnico em Agropecuária & 165 & 95 & 57 & 158 & 90 & 57 \\
\hline Discentes Técnico em Administração & 99 & 34 & 34 & 75 & 40 & 53 \\
\hline Discentes Técnico em Alimentos & 78 & 33 & 42 & 68 & 38 & 56 \\
\hline Discentes Técnico em Contabilidade & 65 & 26 & 40 & 52 & 27 & 51 \\
\hline Discentes Técnico em Farmácia & - & - & - & 33 & 29 & 87 \\
\hline Discentes Técnico em Geoprocessamento & 84 & 19 & 22 & 75 & 31 & 41 \\
\hline Discentes Técnico em Informática & 136 & 48 & 35 & 115 & 60 & 52 \\
\hline Discentes Técnico em Meio Ambiente & 97 & 28 & 28 & 79 & 37 & 46 \\
\hline Discentes Técnico em Paisagismo & 93 & 21 & 22 & 87 & 34 & 39 \\
\hline Discentes Técnico em Secretariado & 33 & 23 & 69 & 44 & 29 & 65 \\
\hline Discentes Técnico em Zootecnia & - & - & - & 29 & 18 & 62 \\
\hline Discentes Geoprocessamento & 107 & 62 & 57 & 109 & 57 & 52 \\
\hline Discentes Gestão Ambiental & - & - & - & 47 & 32 & 68 \\
\hline Discentes Gestão de Cooperativas & 142 & 35 & 24 & 157 & 86 & 54 \\
\hline Discentes Sistemas para Internet & 116 & 12 & 10 & 134 & 72 & 53 \\
\hline Discentes da Pós-Graduação & 34 & 14 & 41 & 31 & 17 & 54 \\
\hline TOTAL & 1.495 & 552 & 37 & 1.551 & 892 & 57 \\
\hline
\end{tabular}

Fonte: pesquisa

Analisando a tabela acima se observa que praticamente todos os segmentos tiveram aumento de participação na pesquisa de Autoavaliação comparando 2014 e 2016. Isso é fruto do trabalho realizado pela CSA do Politécnico que promoveu uma série de ações para 
incentivar a ampla participação de todos. Tais ações envolveram participação da CSA nas reuniões do Politécnico a fim de sensibilizar os participantes, divulgação por meio de banners em todos os blocos do Politécnico (ao todos são seis), visitas às salas de aulas dos alunos para sensibilização, auxílio na participação do público-alvo na avaliação, publicação de notícias nos sítios da CSA e do Politécnico divulgando o processo, dentre outras ações.

A partir da conclusão da pesquisa de Autoavaliação no Colégio Politécnico da UFSM, alguns indicadores foram observados e serão apresentados nas tabelas a seguir. Para todas as tabelas, a legendas das respostas é a seguinte: E (Excelente); B (Bom); RE (Regular); RU (Ruim); P (Péssimo); NSA (Não se Aplica). Além disso, para fins de análise dos resultados tomam-se como positivo se a soma dos percentuais das respostas "Excelente" e "Bom" for maior ou igual a $60 \%$, e como negativo se a soma dos percentuais das respostas "Regular", "Ruim" e "Péssimo" for maior ou igual a 40\%. As respostas "Não se Aplica" são apresentadas, mas foram descartadas da análise.

Assim, a tabela 2 apresenta os resultados da pesquisa referente às "Questões Gerais". As Questões Gerais foram aplicadas a todos os segmentos do Politécnico, sendo divididas nas 5 dimensões do SINAES, totalizam 23 questões. No que tange às Questões Gerais, estavam habilitados a responder a avaliação um total de 1.305 participantes. Destes, 703 responderam o instrumento, correspondendo a um total de 53,86\%.

Tabela 2 - Resultados referentes às Questões Gerais

\begin{tabular}{|l|c|c|c|c|c|c|}
\hline \multicolumn{1}{|c|}{ Perguntas } & \multicolumn{7}{|c|}{ Respostas (em Percentual) } \\
\cline { 2 - 8 } & E & B & RE & RU & P & NSA \\
\hline $\begin{array}{l}\text { Como você avalia a divulgação dos resultados da } \\
\text { Pesquisa de Autoavaliação Institucional na sua } \\
\text { unidade/subunidade? }\end{array}$ & 21,48 & 45,37 & 18,35 & 3,56 & 0,85 & 10,39 \\
\hline $\begin{array}{l}\text { Como você avalia a utilização dos resultados da } \\
\text { Pesquisa de Autoavaliação Institucional como } \\
\text { subsídio à revisão, proposição e implementação de } \\
\text { ações na sua unidade/subunidade? }\end{array}$ & 17,64 & 48,36 & 17,78 & 2,99 & 0,29 & 12,94 \\
\hline $\begin{array}{l}\text { Como você avalia as açães voltadas para a inclusão } \\
\text { social promovidas pela Instituição? }\end{array}$ & 17,22 & 50,36 & 19,06 & 2,27 & 0,14 & 10,95 \\
\hline $\begin{array}{l}\text { Como você avalia a acessibilidade da } \\
\text { unidade/subunidade em que você atua? }\end{array}$ & 27,03 & 49,22 & 14,94 & 2,56 & 0,14 & 6,11 \\
\hline $\begin{array}{l}\text { Como você avalia a gestão ambiental da } \\
\text { Instituição? da UnSM é construir e difundir }\end{array}$ & 27,46 & 47,23 & 15,64 & 3,56 & 0,99 & 5,12 \\
\hline $\begin{array}{l}\text { A missão da UFSM } \\
\text { conhecimento, comprometida com a formação de } \\
\text { pessoas capazes de inovar e contribuir com o } \\
\text { desenvolvimento da sociedade, de modo } \\
\text { sustentável. Como você avalia a atuação da } \\
\text { Instituição no cumprimento da sua missão? }\end{array}$ & 28,17 & 52,21 & 13,80 & 2,13 & 0,43 & 3,26 \\
\hline $\begin{array}{l}\text { Como você avalia os canais de comunicação } \\
\text { interna entre os diversos setores da Instituição? }\end{array}$ & 16,64 & 51,49 & 22,76 & 3,28 & 1,14 & 4,69 \\
\hline $\begin{array}{l}\text { Como você avalia os canais de comunicação da } \\
\text { Instituição com a comunidade externa? }\end{array}$ & 14,79 & 46,80 & 26,03 & 5,69 & 0,43 & 6,26 \\
\hline $\begin{array}{l}\text { Como você avalia o Ambiente Virtual de Ensino e } \\
\text { Aprendizagem (AVEA) oferecido pela Instituição? }\end{array}$ & 19,77 & 44,67 & 14,79 & 2,42 & 0,57 & 17,78 \\
\hline
\end{tabular}




\begin{tabular}{|c|c|c|c|c|c|c|}
\hline \multirow{2}{*}{ Perguntas } & \multicolumn{6}{|c|}{ Respostas (em Percentual) } \\
\hline & $\mathbf{E}$ & B & $\mathbf{R E}$ & RU & $\mathbf{P}$ & NSA \\
\hline $\begin{array}{l}\text { Como você avalia a capacitação e a qualificação } \\
\text { dos servidores docentes e técnico-administrativos } \\
\text { em educação nos diversos setores administrativos } \\
\text { da Instituição? }\end{array}$ & 25,89 & 56,61 & 14,09 & 1,14 & 0,28 & 1,99 \\
\hline $\begin{array}{l}\text { Como você avalia o acesso e a funcionalidade dos } \\
\text { portais institucionais (Portal do RH, Portal do } \\
\text { Aluno, Portal do Professor, entre outros)? }\end{array}$ & 36,85 & 52,20 & 8,96 & 0,57 & 0,14 & 1,28 \\
\hline $\begin{array}{l}\text { Como você avalia a disponibilidade e a atualização } \\
\text { do acervo das bibliotecas que você utiliza? }\end{array}$ & 24,03 & 53,35 & 15,09 & 1,56 & 0,14 & 5,83 \\
\hline $\begin{array}{l}\text { Como você avalia os serviços terceirizados } \\
\text { disponibilizados na Instituição (recepção, limpeza, } \\
\text { manutenção e segurança)? }\end{array}$ & 24,32 & 49,79 & 20,20 & 3,13 & 1,56 & 1,00 \\
\hline $\begin{array}{l}\text { Como você avalia a prestação de serviços privados } \\
\text { disponíveis na Instituição (restaurantes/lancherias e } \\
\text { reprografias)? }\end{array}$ & 12,52 & 42,67 & 30,58 & 8,96 & 2,99 & 2,28 \\
\hline $\begin{array}{l}\text { Como você avalia os horários de atendimento dos } \\
\text { serviços privados disponíveis à comunidade } \\
\text { (transporte coletivo, restaurantes/lancherias e } \\
\text { reprografias)? }\end{array}$ & 8,39 & 37,13 & 34,85 & 12,66 & 4,84 & 2,13 \\
\hline $\begin{array}{l}\text { Como você avalia os horários de atendimento dos } \\
\text { serviços internos disponíveis à comunidade } \\
\text { universitária (restaurante universitário, bibliotecas } \\
\text { e setores administrativos)? }\end{array}$ & 16,65 & 54,77 & 21,91 & 3,41 & 0,42 & 2,84 \\
\hline $\begin{array}{l}\text { Como você avalia as condições de infraestrutura da } \\
\text { Instituição? }\end{array}$ & 29,73 & 54,48 & 13,23 & 1,85 & 0,14 & 0,57 \\
\hline $\begin{array}{l}\text { Como você avalia as condições de infraestrutura de } \\
\text { sua unidade/subunidade? }\end{array}$ & 40,97 & 50,64 & 6,26 & 1,14 & 0,14 & 0,85 \\
\hline $\begin{array}{l}\text { Como você avalia a disponibilidade, conservação e } \\
\text { acesso aos equipamentos na Instituição? }\end{array}$ & 23,76 & 60,74 & 12,23 & 2,28 & 0,28 & 0,71 \\
\hline $\begin{array}{l}\text { Como você avalia a disponibilidade e o acesso à } \\
\text { internet e à intranet na Instituição? }\end{array}$ & 17,35 & 35,42 & 30,59 & 11,10 & 4,69 & 0,85 \\
\hline $\begin{array}{l}\text { Como você avalia as condições das instalações } \\
\text { sanitárias que você utiliza? }\end{array}$ & 28,45 & 49,64 & 18,07 & 2,56 & 0,57 & 0,71 \\
\hline $\begin{array}{l}\text { Como você avalia a disponibilidade e } \text { a } \\
\text { conservação dos espaços de convivência que você } \\
\text { utiliza? }\end{array}$ & 28,17 & 57,32 & 12,52 & 0,85 & 0,14 & 1,00 \\
\hline
\end{tabular}

Fonte: pesquisa

Com base nos resultados da tabela acima, observa-se que os pontos positivos que mais se destacaram foram: Divulgação e Utilização dos Resultados da Pesquisa de Autoavaliação; Conhecimento do PDI da UFSM; Ações voltadas para Inclusão Social; Acessibilidade; Gestão Ambiental; Cumprimento da Missão da UFSM; Canais de Comunicação Interna e Externa; Ambiente Virtual de Ensino e Aprendizagem; Capacitação e Qualificação dos Servidores; Funcionalidade dos Portais Institucionais; Disponibilidade e Atualização do Acervo Bibliográfico; Serviços Terceirizados; e Infraestrutura Física. Aqui os pontos negativos observados foram: Horários de Atendimento dos Serviços Privados (48\%); e Disponibilidade e Acesso à Internet (45\%).

A seguir, a tabela 3, apresenta dos resultados da pesquisa em relação ao Segmento "Gestor". Esse bloco de questões possui 3 dimensões do SINAES totalizando 10 questões. Pertencem a este segmento, aqueles servidores que possuem cargos de direção ou funções gratificadas. No que tange ao Segmento Gestor, estavam habilitados a participar do processo de avaliação um total de 24 gestores. Destes, 23 responderam o instrumento, correspondendo a um total de $95,80 \%$. 
Tabela 3 - Resultados referentes ao Segmento "Gestor"

\begin{tabular}{|c|c|c|c|c|c|c|}
\hline \multirow{2}{*}{ Perguntas } & \multicolumn{6}{|c|}{ Respostas (em Percentual) } \\
\hline & $\mathbf{E}$ & B & $\mathbf{R E}$ & $\mathbf{R U}$ & $\mathbf{P}$ & NSA \\
\hline $\begin{array}{l}\text { Como você avalia a participação efetiva dos } \\
\text { responsáveis (coordenadores de curso, docentes, } \\
\text { discentes e técnico-administrativos em educação) } \\
\text { envolvidos no processo de elaboração e } \\
\text { acompanhamento do(s) Projeto(s) Pedagógico(s) de } \\
\text { Curso(s)? }\end{array}$ & 65,30 & 21,70 & 13,00 & - & - & - \\
\hline $\begin{array}{l}\text { Como você avalia o processo de gestão na sua } \\
\text { unidade/subunidade em relação ao alcance dos } \\
\text { objetivos propostos? }\end{array}$ & 30,40 & 60,80 & 8,60 & - & - & - \\
\hline $\begin{array}{l}\text { Como você avalia o acesso pelos discentes aos } \\
\text { programas voltados para a assistência estudantil? }\end{array}$ & 21,90 & 60,80 & 13,00 & - & - & - \\
\hline $\begin{array}{l}\text { Como você avalia a divulgação e o apoio } \\
\text { institucional para a participação da comunidade } \\
\text { universitária em eventos científicos, técnicos ou } \\
\text { culturais? }\end{array}$ & 17,50 & 52,10 & 30,40 & - & - & - \\
\hline $\begin{array}{l}\text { Como você avalia a política de acompanhamento } \\
\text { do egresso da Instituição? }\end{array}$ & - & 26,20 & 56,50 & 13,00 & 4,30 & - \\
\hline $\begin{array}{l}\text { Como você avalia os critérios de distribuição } \\
\text { orçamentária entre as unidades/subunidades da } \\
\text { UFSM? }\end{array}$ & 21,90 & 30,40 & 26,00 & - & - & 21,70 \\
\hline $\begin{array}{l}\text { Como você avalia a alocação de recursos para a } \\
\text { manutenção das instalações e atualização de } \\
\text { equipamentos e materiais na } \\
\text { unidade/subunidade? }\end{array}$ & 30,50 & 65,20 & 4,30 & - & - & - \\
\hline $\begin{array}{l}\text { Como você avalia os recursos financeiros } \\
\text { disponibilizados para as políticas e ações de ensino } \\
\text { na Instituição? }\end{array}$ & 21,90 & 52,20 & 17,30 & - & - & 8,60 \\
\hline $\begin{array}{l}\text { Como você avalia os recursos financeiros } \\
\text { disponibilizados para as políticas e ações de } \\
\text { pesquisa na Instituição? }\end{array}$ & 21,80 & 56,60 & 17,30 & - & - & 4,30 \\
\hline $\begin{array}{l}\text { Como você avalia os recursos financeiros } \\
\text { disponibilizados para as políticas e ações de } \\
\text { extensão na Instituição? }\end{array}$ & 21,90 & 43,50 & 26,00 & - & - & 8,60 \\
\hline
\end{tabular}

Fonte: pesquisa

Com base nos resultados da tabela acima, observa-se que os pontos positivos que mais se destacaram foram: Participação no Processo de Elaboração e Acompanhamento dos Projetos Pedagógicos de Curso (PPCs); Processo de Gestão em relação aos Objetivos Propostos; Programas voltados à Assistência Estudantil; Divulgação e Apoio à Participação da Comunidade em Eventos Científicos; Manutenção das Instalações e Atualização dos Equipamentos; e Recursos Financeiros disponibilizados para Ensino, Pesquisa e Extensão. Da mesma forma que nas "Questões Gerais", o único ponto negativo observado neste segmento tratou da Política de Acompanhamento de Egressos, cujas respostas foram de aproximadamente $73 \%$.

A seguir, a tabela 4, apresenta dos resultados da pesquisa em relação ao Segmento "Docentes". No segmento Docentes foram avaliadas 3 Dimensões do SINAES, totalizando 13 questões. No que tange ao Segmento Docentes, estavam habilitados a participar do processo de avaliação um total de 93 docentes. Destes, 75 responderam o instrumento, correspondendo a um total de $80,64 \%$. 
Tabela 4 - Resultados referentes ao Segmento "Docentes"

\begin{tabular}{|c|c|c|c|c|c|c|}
\hline \multirow{2}{*}{ Perguntas } & \multicolumn{6}{|c|}{ Respostas (em Percentual) } \\
\hline & $\mathbf{E}$ & B & $\mathbf{R E}$ & RU & $\mathbf{P}$ & NSA \\
\hline $\begin{array}{l}\text { Como você avalia as condições que a UFSM lhe } \\
\text { proporciona para exercer suas atividades de ensino, } \\
\text { pesquisa e extensão? }\end{array}$ & 31,60 & 59,30 & 7,80 & 1,30 & - & - \\
\hline $\begin{array}{l}\text { Como você avalia a participação dos docentes no } \\
\text { processo de elaboração e acompanhamento do(s) } \\
\text { Projeto(s) Pedagógico(s) de Curso(s)? }\end{array}$ & 22,50 & 48,70 & 21,00 & 3,90 & 3,90 & - \\
\hline $\begin{array}{l}\text { Como você avalia o apoio aos discentes para a } \\
\text { participação em eventos, divulgação de trabalhos e } \\
\text { produção intelectual? }\end{array}$ & 25,10 & 52,60 & 17,10 & 3,90 & - & 1,30 \\
\hline $\begin{array}{l}\text { Como você avalia a disponibilidade de bolsas } \\
\text { acadêmicas? }\end{array}$ & 21,20 & 56,60 & 13,10 & 2,60 & - & 6,50 \\
\hline $\begin{array}{l}\text { Como você avalia o(s) laboratório(s) da sua } \\
\text { unidade quanto à qualificação de pessoal técnico? }\end{array}$ & 26,40 & 56,60 & 10,50 & 1,30 & 1,30 & 3,90 \\
\hline $\begin{array}{l}\text { Como você avalia as ações promovidas pela Pró- } \\
\text { Reitoria de Gestão de Pessoas voltadas à melhoria } \\
\text { da qualidade de vida do servidor? }\end{array}$ & 22,50 & 52,60 & 13,10 & - & 1,30 & 10,50 \\
\hline $\begin{array}{l}\text { Como você avalia, considerando as relações de } \\
\text { trabalho, o seu relacionamento com os colegas? }\end{array}$ & 39,50 & 48,70 & 9,20 & 2,60 & - & - \\
\hline $\begin{array}{l}\text { Como você avalia, considerando as relações de } \\
\text { trabalho, o seu relacionamento com a chefia? }\end{array}$ & 57,90 & 31,70 & 6,50 & 3,90 & - & - \\
\hline $\begin{array}{l}\text { Como você avalia as condições que a UFSM lhe } \\
\text { proporciona para sua qualificação profissional? }\end{array}$ & 35,60 & 50,00 & 10,50 & - & 1,30 & 2,60 \\
\hline $\begin{array}{l}\text { Como você avalia o apoio aos docentes para a } \\
\text { participação em eventos, divulgação de trabalhos e } \\
\text { produção intelectual? }\end{array}$ & 31,70 & 46,00 & 18,40 & - & 1,30 & 2,60 \\
\hline $\begin{array}{l}\text { Como você avalia a informatização das rotinas } \\
\text { acadêmicas e administrativas integrantes do } \\
\text { Sistema de Informações para o Ensino (SIE)? }\end{array}$ & 10,50 & 52,60 & 31,70 & 2,60 & 1,30 & 1,30 \\
\hline $\begin{array}{l}\text { Como você avalia o(s) laboratório(s) da sua } \\
\text { unidade quanto à conservação, à expansão e às } \\
\text { normas de segurança? }\end{array}$ & 30,40 & 53,90 & 11,80 & - & - & 3,90 \\
\hline $\begin{array}{l}\text { Como você avalia a Biblioteca Setorial da sua } \\
\text { unidade quanto às instalações, acervo e condições } \\
\text { de estudo? }\end{array}$ & 25,10 & 51,30 & 22,30 & 1,30 & - & - \\
\hline
\end{tabular}

Fonte: pesquisa

Com base nos resultados da tabela acima, observa-se que os pontos positivos que mais se destacaram foram: Condições Oferecidas pela UFSM para o Exercício das Atividades de Ensino, Pesquisa e Extensão; Participação Docente nos Processos de Elaboração e Acompanhamento dos PPCs; Apoio aos Docentes e aos Discentes na Participação em Eventos Científicos; Disponibilidade de Bolsas Acadêmicas; Laboratórios; Ações promovidas pela Pró-Reitoria de Gestão de Pessoas voltadas aos Servidores; Relacionamento com os Colegas e com a Chefia; Condições Oferecidas para Qualificação Profissional; Qualidade dos Sistemas Internos de Rotinas Acadêmicas e Administrativas; e Instalações, Acervo e Condições da Biblioteca Setorial. Neste segmento não foram observados pontos negativos.

A tabela 5, na sequência, apresenta dos resultados da pesquisa em relação ao Segmento "Técnico-Administrativos em Educação". O segmento dos TécnicoAdministrativos em Educação avaliou 1 Dimensão dos SINAES, totalizando 10 questões. No que tange a este segmento, estavam habilitados a participar do processo de avaliação um total de 34 técnico-administrativos. Destes, 31 responderam o instrumento, correspondendo a um total de $91,20 \%$. 
Tabela 5 - Resultados referentes ao Segmento "Técnico-Administrativos em Educação"

\begin{tabular}{|c|c|c|c|c|c|c|}
\hline \multirow{2}{*}{ Perguntas } & \multicolumn{6}{|c|}{ Respostas (em Percentual) } \\
\hline & $\mathbf{E}$ & B & $\mathbf{R E}$ & RU & $\mathbf{P}$ & NSA \\
\hline $\begin{array}{l}\text { Como você avalia o incentivo da Instituição na } \\
\text { qualificação do servidor (graduação, } \\
\text { especialização, mestrado e doutorado)? }\end{array}$ & 6,50 & 64,50 & 29,00 & - & - & - \\
\hline $\begin{array}{l}\text { Como você avalia as ações promovidas pela Pró- } \\
\text { Reitoria de Gestão de Pessoas voltadas à melhoria } \\
\text { da qualidade de vida do servidor? }\end{array}$ & 9,60 & 80,60 & 6,40 & - & - & 3,20 \\
\hline $\begin{array}{l}\text { Como você avalia o incentivo da Instituição à sua } \\
\text { participação em eventos de capacitação fora da } \\
\text { UFSM (recursos financeiros e liberação pela } \\
\text { chefia)? }\end{array}$ & 16,20 & 61,30 & 19,30 & - & - & 3,20 \\
\hline $\begin{array}{l}\text { Como você avalia a implementação e a divulgação } \\
\text { do programa de avaliação de desempenho } \\
\text { funcional na UFSM? }\end{array}$ & 6,40 & 77,50 & 16,10 & - & - & - \\
\hline $\begin{array}{l}\text { Como você avalia as reuniões periódicas no seu } \\
\text { setor de trabalho, para tratar de interesses da } \\
\text { equipe? }\end{array}$ & 22,60 & 54,90 & 16,10 & 3,20 & 3,20 & - \\
\hline $\begin{array}{l}\text { Como você avalia, considerando as relações de } \\
\text { trabalho, o seu relacionamento com os colegas? }\end{array}$ & 48,40 & 51,60 & - & - & - & - \\
\hline $\begin{array}{l}\text { Como você avalia, considerando as relações de } \\
\text { trabalho, o seu relacionamento com a chefia? }\end{array}$ & 51,60 & 48,40 & - & - & - & - \\
\hline $\begin{array}{l}\text { Como você avalia a sua satisfação em relação ao } \\
\text { trabalho que realiza? }\end{array}$ & 38,80 & 54,80 & 6,40 & - & - & - \\
\hline $\begin{array}{l}\text { Como você avalia a condução do processo de } \\
\text { avaliação, pela Instituição, no período do estágio } \\
\text { probatório? }\end{array}$ & 22,60 & 48,40 & 9,70 & - & - & 19,30 \\
\hline $\begin{array}{l}\text { Como você avalia a informatização das rotinas } \\
\text { acadêmicas e administrativas integrantes do } \\
\text { Sistema de Informações para o Ensino (SIE)? }\end{array}$ & - & 54,80 & 29,10 & 6,40 & - & 9,70 \\
\hline
\end{tabular}

Fonte: pesquisa

Com base nos resultados da tabela acima, observa-se que os pontos positivos que mais se destacaram foram: Incentivo a Instituição para Qualificação; Ações promovidas pela PróReitoria de Gestão de Pessoas voltadas aos Servidores; Incentivo à Participação em Eventos de Qualificação fora da UFSM; Implementação e Divulgação do Programa de Avaliação de Desempenho; Reuniões Periódicas no Setor de Trabalho. Relações de trabalho, tanto com os colegas como em relação à Chefia; Satisfação em relação ao Trabalho que Realiza; Condução do Processo de Avaliação, no período do estágio probatório; e Qualidade dos Sistemas Internos de Rotinas Acadêmicas e Administrativas. Neste segmento não foram observados pontos negativos.

Já a tabela 6 dedica-se a apresentar os resultados da pesquisa em relação ao Segmento "Discentes do Ensino Médio e dos Cursos Técnicos". Para este segmento foram disponibilizadas 11 questões englobando 3 dimensões do SINAES: Desenvolvimento Institucional, Políticas Acadêmicas e Políticas de Gestão. Em se tratando do Ensino Médio, estavam habilitados a participar do processo de avaliação um total de 922 alunos. Destes, 498 responderam o instrumento, correspondendo a um total de $54,01 \%$. 
Tabela 6 - Resultados referentes ao Segmento "Discentes do Ensino Médio e dos Cursos Técnicos"

\begin{tabular}{|c|c|c|c|c|c|c|}
\hline \multirow{2}{*}{ Perguntas } & \multicolumn{6}{|c|}{ Respostas (em Percentual) } \\
\hline & $\mathbf{E}$ & B & $\mathbf{R E}$ & RU & $\mathbf{P}$ & NSA \\
\hline $\begin{array}{l}\text { Como você avalia a contribuição dos planos de } \\
\text { ensino para a sua formação acadêmica no que diz } \\
\text { respeito à atualização, conteúdos e bibliografias } \\
\text { das disciplinas? }\end{array}$ & 30,20 & 52,30 & 13,90 & 1,50 & 0,19 & 2,00 \\
\hline $\begin{array}{l}\text { Como você avalia o } \text { acompanhamento, } \\
\text { cumprimento e divulgação dos trabalhos de } \\
\text { conclusão de curso? }\end{array}$ & 15,81 & 46,60 & 14,30 & 3,70 & 1,10 & 18,40 \\
\hline $\begin{array}{l}\text { Como você avalia a divulgação e o acesso aos } \\
\text { programas voltados para a assistência estudantil? }\end{array}$ & 19,50 & 48,40 & 19,50 & 3,30 & 1,10 & 8,20 \\
\hline $\begin{array}{l}\text { Como você avalia a divulgação e o apoio da } \\
\text { coordenação do curso para a sua participação em } \\
\text { eventos científicos, técnicos ou culturais? }\end{array}$ & 31,90 & 40,80 & 17,60 & 3,30 & 2,59 & 3,90 \\
\hline 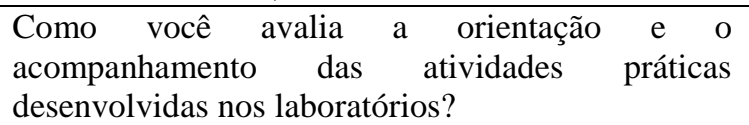 & 29,70 & 47,90 & 17,40 & 2,60 & 0,70 & 1,70 \\
\hline $\begin{array}{l}\text { Como você avalia o apoio e o incentivo da sua } \\
\text { unidade de ensino à organização dos estudantes? }\end{array}$ & 25,20 & 48,20 & 16,50 & 2,80 & 2,00 & 5,39 \\
\hline $\begin{array}{l}\text { Como você avalia o corpo docente, quanto à sua } \\
\text { experiência, conhecimento, dedicação e } \\
\text { comprometimento, em relação à proposta do curso? }\end{array}$ & 41,61 & 42,30 & 13,20 & 1,70 & 0,70 & 0,40 \\
\hline $\begin{array}{l}\text { Como você avalia a atuação do diretor de sua } \\
\text { unidade de ensino/campus, considerando a } \\
\text { melhoria contínua e o atendimento às necessidades } \\
\text { dos estudantes? }\end{array}$ & 33,61 & 43,80 & 13,40 & 1,30 & 1,70 & 6,10 \\
\hline $\begin{array}{l}\text { Como você avalia a atuação do coordenador do seu } \\
\text { curso, considerando a melhoria contínua e o } \\
\text { atendimento às necessidades dos estudantes? }\end{array}$ & 47,50 & 37,50 & 10,20 & 1,50 & 2,00 & 1,30 \\
\hline $\begin{array}{l}\text { Como você avalia o funcionamento e } \text { e } \\
\text { acompanhamento das atividades de prática } \\
\text { profissional e/ou estágio pela coordenação do } \\
\text { curso? }\end{array}$ & 26,00 & 42,50 & 12,80 & 2,60 & 1,30 & 14,80 \\
\hline $\begin{array}{l}\text { Como você avalia o funcionamento e o } \\
\text { atendimento da secretaria do seu curso, } \\
\text { considerando a melhoria contínua e o atendimento } \\
\text { às necessidades dos estudantes? }\end{array}$ & 29,90 & 50,80 & 14,30 & 1,30 & 0,40 & 3,30 \\
\hline
\end{tabular}

Fonte: pesquisa

Com base nos resultados da tabela acima, observa-se que os pontos positivos que mais se destacaram foram: Contribuição dos Planos de Ensino para Formação Acadêmica; Acompanhamento, Cumprimento e Divulgação dos Trabalhos de Conclusão de Curso; Divulgação e Acesso aos Programas de Assistência Estudantil; Divulgação e Apoio da Coordenação do Curso para Participação em Eventos; Orientação e Acompanhamento das Atividades em Laboratório; Apoio e Incentivo à Organização dos Estudantes; Qualidade do Corpo Docente; Atuação do Diretor de Unidade; Atuação do Coordenador do Curso; Funcionamento e Acompanhamento das Atividades de Prática Profissional e/ou Estágio pela Coordenação; e Funcionamento e Atendimento da Secretaria do Curso. Neste segmento não foram observados pontos negativos.

A tabela 7 apresenta os resultados da pesquisa em relação ao Segmento "Discentes dos Cursos de Graduação". Para este segmento foram disponibilizadas 11 questões englobando 3 dimensões do SINAES: Desenvolvimento Institucional, Políticas Acadêmicas e Políticas de Gestão. Em se tratando aos Discentes dos Cursos de Graduação, estavam habilitados a 
participar do processo de avaliação um total de 447 alunos. Destes, 247 responderam o instrumento, correspondendo a um total de $55,25 \%$.

Tabela 7 - Resultados referentes ao Segmento "Discentes dos Cursos de Graduação"

\begin{tabular}{|l|c|c|c|c|c|c|}
\hline \multicolumn{1}{|c|}{ Perguntas } & \multicolumn{5}{|c|}{ Respostas (em Percentual) } \\
\cline { 2 - 8 } & E & B & RE & RU & P & NSA \\
\hline $\begin{array}{l}\text { Como você avalia a contribuição dos planos de } \\
\text { ensino para a sua formação acadêmica no que diz } \\
\text { respeito à atualização, conteúdos e bibliografias }\end{array}$ & 26,31 & 53,40 & 15,80 & 2,00 & 0,80 & 1,60 \\
das disciplinas? & & & & & & \\
\hline $\begin{array}{l}\text { Como você avalia o acompanhamento, } \\
\text { cumprimento e divulgação dos trabalhos de } \\
\text { conclusão de curso? }\end{array}$ & 13,80 & 51,00 & 17,00 & 3,20 & 0,40 & 14,60 \\
\hline $\begin{array}{l}\text { Como você avalia a divulgação e o acesso aos } \\
\text { programas voltados para a assistência estudantil? }\end{array}$ & 14,20 & 48,20 & 27,90 & 4,50 & 0,79 & 4,50 \\
\hline $\begin{array}{l}\text { Como você avalia a divulgação o apoio da } \\
\text { coordenação do curso para a sua participação em } \\
\text { eventos científicos, técnicos ou culturais? }\end{array}$ & 33,20 & 41,70 & 17,00 & 4,90 & 0,80 & 2,40 \\
\hline $\begin{array}{l}\text { Como você avalia a orientação e o } \\
\text { acompanhamento das atividades práticas } \\
\text { desenvolvidas nos laboratórios? }\end{array}$ & 24,70 & 47,00 & 19,00 & 1,60 & 2,00 & 5,70 \\
\hline $\begin{array}{l}\text { Como você avalia o apoio e o incentivo da sua } \\
\text { unidade de ensino à organização dos estudantes? }\end{array}$ & 18,61 & 54,70 & 19,00 & 3,20 & 0,40 & 4,00 \\
\hline $\begin{array}{l}\text { Como você avalia o corpo docente, quanto à sua } \\
\text { experiência, conhecimento, dedicação e } \\
\text { comprometimento, em relação à proposta do curso? }\end{array}$ & 38,50 & 40,10 & 18,20 & 0,80 & 1,20 & 1,20 \\
\hline $\begin{array}{l}\text { Como você avalia a atuação do diretor de sua } \\
\text { unidade de ensino/campus, considerando a } \\
\text { melhoria contínua e o atendimento às necessidades } \\
\text { dos estudantes? }\end{array}$ & 28,30 & 50,20 & 12,60 & 0,80 & 0,40 & 7,70 \\
\hline $\begin{array}{l}\text { Como você avalia a atuação do coordenador do seu } \\
\text { curso, considerando a melhoria contínua e o } \\
\text { atendimento às necessidades dos estudantes? }\end{array}$ & 40,90 & 40,90 & 13,00 & 2,80 & 0,80 & 1,60 \\
\hline $\begin{array}{l}\text { Como você avalia o funcionamento e o } \\
\text { acompanhamento das atividades de prática } \\
\text { profissional e/ou estágio pela coordenação do } \\
\text { curso? }\end{array}$ & 20,61 & 41,70 & 17,00 & 2,40 & 2,40 & 15,80 \\
\hline $\begin{array}{l}\text { Como você avalia o funcionamento e o } \\
\text { atendimento da secretaria do seu curso, } \\
\text { considerando a melhoria contínua e o atendimento } \\
\text { às necessidades dos estudantes? }\end{array}$ & 23,90 & 53,40 & 14,60 & 2,80 & - & 5,30 \\
\hline
\end{tabular}

Fonte: pesquisa

Com base nos resultados da tabela acima, observa-se que os pontos positivos que mais se destacaram foram: Contribuição dos Planos de Ensino para Formação Acadêmica; Acompanhamento, Cumprimento e Divulgação dos Trabalhos de Conclusão de Curso; Divulgação e Acesso aos Programas de Assistência Estudantil; Divulgação e Apoio da Coordenação do Curso para Participação em Eventos; Orientação e Acompanhamento das Atividades em Laboratório; Apoio e Incentivo à Organização dos Estudantes; Qualidade do Corpo Docente; Atuação do Diretor de Unidade; Atuação do Coordenador do Curso; Funcionamento e Acompanhamento das Atividades de Prática Profissional e/ou Estágio pela Coordenação; e Funcionamento e Atendimento da Secretaria do Curso. Neste segmento não foram observados pontos negativos. 
Finalmente, a tabela 8 apresenta os resultados da pesquisa em relação ao Segmento "Discentes da Pós-Graduação". Para este segmento foram disponibilizadas 12 questões englobando 3 dimensões do SINAES: Desenvolvimento Institucional, Políticas Acadêmicas e Políticas de Gestão. Em se tratando da Pós-Graduação, estavam habilitados a participar do processo de avaliação um total de 31 alunos. Destes, 17 responderam o instrumento, correspondendo a um total de $54,83 \%$.

Tabela 8 - Resultados referentes ao Segmento "Discentes da Pós-Graduação"

\begin{tabular}{|c|c|c|c|c|c|c|}
\hline \multirow{2}{*}{ Perguntas } & \multicolumn{6}{|c|}{ Respostas (em Percentual) } \\
\hline & $\mathbf{E}$ & B & RE & $\mathbf{R U}$ & $\mathbf{P}$ & NSA \\
\hline $\begin{array}{l}\text { Como você avalia a contribuição dos planos de } \\
\text { ensino para a sua formação acadêmica, no que diz } \\
\text { respeito à atualização, conteúdos e bibliografias } \\
\text { das disciplinas? }\end{array}$ & 35,29 & 58,83 & - & 5,88 & - & - \\
\hline $\begin{array}{l}\text { Como você avalia o } \text { acompanhamento, } \\
\text { cumprimento e divulgação dos trabalhos de } \\
\text { conclusão de curso? }\end{array}$ & 17,66 & 23,53 & 35,29 & 5,88 & 5,88 & 11,76 \\
\hline $\begin{array}{l}\text { Como você avalia a divulgação e o apoio da } \\
\text { coordenação do curso para a sua participação em } \\
\text { eventos científicos, técnicos ou culturais? }\end{array}$ & 29,41 & 47,05 & 17,66 & - & - & 5,88 \\
\hline $\begin{array}{l}\text { Como você avalia a orientação } \begin{array}{c}\text { e o } \\
\text { acompanhamento das } \\
\text { atividades } \\
\text { desenvolvidas nos laboratórios? }\end{array} \\
\end{array}$ & 23,53 & 58,83 & 11,76 & 5,88 & - & - \\
\hline $\begin{array}{l}\text { Como você avalia o acesso e o treinamento } \\
\text { oferecidos pela Instituição, para busca bibliográfica } \\
\text { em portais de periódicos? }\end{array}$ & 11,76 & 41,18 & 29,41 & 11,76 & - & 5,88 \\
\hline $\begin{array}{l}\text { Como você avalia os critérios adotados para a } \\
\text { concessão de bolsas? }\end{array}$ & 11,76 & - & 17,66 & 5,88 & 11,76 & 52,94 \\
\hline $\begin{array}{l}\text { Como você avalia o corpo docente quanto à sua } \\
\text { experiência, conhecimento, dedicação e } \\
\text { comprometimento, em relação à proposta do curso? }\end{array}$ & 52,94 & 47,06 & - & - & - & - \\
\hline $\begin{array}{l}\text { Como você avalia a atuação do diretor do seu } \\
\text { centro de ensino/campus, considerando a melhoria } \\
\text { contínua e o atendimento às necessidades dos } \\
\text { estudantes? }\end{array}$ & 41,18 & 29,41 & 23,53 & - & - & 5,88 \\
\hline $\begin{array}{l}\text { Como você avalia a atuação do coordenador do seu } \\
\text { curso, considerando a melhoria contínua e o } \\
\text { atendimento às necessidades dos estudantes? }\end{array}$ & 41,18 & 41,18 & 11,76 & - & - & 5,88 \\
\hline $\begin{array}{l}\text { Como você avalia o funcionamento e o } \\
\text { atendimento da secretaria do seu curso, } \\
\text { considerando a melhoria contínua e o atendimento } \\
\text { às necessidades dos estudantes? }\end{array}$ & 52,94 & 17,65 & 23,53 & 5,88 & - & - \\
\hline $\begin{array}{l}\text { Como você avalia a atuação do seu orientador em } \\
\text { relação ao acompanhamento e orientação do seu } \\
\text { projeto de pós-graduação? }\end{array}$ & 41,18 & 35,29 & 17,65 & 5,88 & - & - \\
\hline $\begin{array}{l}\text { Como você avalia as condições oferecidas para a } \\
\text { realização das pesquisas necessárias ao seu } \\
\text { embasamento acadêmico-profissional? }\end{array}$ & 35,29 & 35,29 & 11,76 & 5,88 & - & 11,76 \\
\hline
\end{tabular}

Fonte: pesquisa

Com base nos resultados da tabela acima, observa-se que os pontos positivos que mais se destacaram foram: Contribuição dos Planos de Ensino para Formação Acadêmica; Divulgação e Apoio da Coordenação para Participação em Eventos; Orientação e Acompanhamento das Atividades em Laboratórios; Qualificação do Corpo Docente; Atuação do Diretor da Unidade, do Coordenador e da Secretaria do Curso; Atuação do Orientador; e 
das Condições Oferecidas para a Realização de Pesquisas. Como pontos negativos foram levantados: Acompanhamento, Cumprimento e Divulgação dos Trabalhos de Conclusão de Curso (45\%); e Acesso e Treinamento Oferecidos para Busca em Portais de Periódicos (40\%).

Diante dos resultados apresentados, pode-se inferir que, segundo a opinião dos respondentes, o Colégio Politécnico da UFSM tem apresentado indicadores altamente satisfatórios no que tange ao processo de Autoavaliação. No entanto, tais resultados devem ser analisados ainda com mais profundidade, pois alguns pontos requerem atenção. Dessa forma, pode-se sugerir a criação de um instrumento para mapear as causas dos pontos negativos e a realização de um trabalho para melhorar ainda mais o que se faz no Colégio Politécnico da UFSM.

\section{CONCLUSÃO}

O processo de autoavaliação institucional é um instrumento extremamente relevante cuja finalidade é contribuir para o contínuo processo de aperfeiçoamento do desempenho da UFSM e das suas Unidades de Ensino, como é o caso do Politécnico. Em termos práticos, este artigo se propôs a apresentar os resultados do processo de autoavaliação do Colégio Politécnico da UFSM. Entende-se que um estudo desta natureza contribua para que a UFSM, suas Unidades e seus Participantes (Gestores, Docentes, Técnico-Administrativos e Discentes) analisem internamente, através de uma participação transparente e proativa dos sujeitos, suas ações, buscando sistematizar dados para analisá-los e interpretá-los com vistas à identificação de práticas bem-sucedidas, assim como a percepção de falhas, deficiências, enganos e omissões, a fim de evitá-los no futuro.

Do ponto de vista dos principais resultados observou-se que em todos os segmentos pesquisados, a quase totalidade das questões avaliadas foram percebidas de maneira positiva, tais como: divulgação dos resultados da autoavaliação institucional para a comunidade da sua unidade; entendimento do PDI para ações de ensino, pesquisa e extensão; participação efetiva dos gestores nas ações de ensino, pesquisa e extensão; avaliação das ações voltadas para a inclusão social promovidas pela UFSM; divulgação dos programas voltados à assistência estudantil; incentivo à participação em eventos (discentes); condições de acesso para pessoas com necessidades especiais; infraestrutura física; relacionamento entre colegas e com a chefia; boas relações entre docentes e discentes; experiência, conhecimento, dedicação e comprometimento do corpo docente; entre outros. Por sua vez também emergiram algumas questões a serem melhoradas, tais como: disponibilidade e acesso à internet; e política de acompanhamento de egressos. Outros pontos negativos foram levantados, mas referem-se especificamente a um ou outro segmento.

Por fim, no desenvolver deste trabalho, intentou-se apresentar um instrumento informacional objetivo, cuja finalidade é auxiliar na busca de mecanismos que permitam a contínua melhoria de todo o planejamento dos processos de ensino e aprendizagem, no que tange ao ensino, à pesquisa e à extensão. Desta forma, conclui-se que os objetivos propostos para este estudo foram atendidos. 


\section{REFERÊNCIAS}

BRASIL. Lei $\mathbf{n}^{0} \mathbf{1 0 . 8 6 1}$, de 14 de abril de 2004. Institui o Sistema Nacional de Avaliação da Educação Superior (SINAES) e dá outras providências. Disponível em: <http://www.inep.gov.br>. Acesso em 07 mai 2017.

MEC - Diretrizes para a avaliação das instituições de educação superior. Brasília: INEP/CONAES, 2004.

DAVIS, C.; GROSBAUM, M. W. Sucesso de todos, compromisso da escola. In: VIEIRA, S. L. (Org.). Gestão da escola: desafios a enfrentar. Rio de Janeiro: DP\&A, 2002.

GIL, A. C. Como elaborar projetos de pesquisa. São Paulo: Atlas, 2007.

LORENTZ, M. H. do N.; AGNOLIN, S. L.; VENTURA, J. L.; TRINDADE, C. C. P.; MADRUGA, L. R. da R. G. Programa de avaliação institucional na Universidade Federal de Santa Maria CPA: funcionamento e descentralização do processo. 2013. Disponível em <http://coral.ufsm.br/avaliacaoufsm/index.php/apresentacao/publicacoes/cpa>. Acesso em 19 jun. 2017.

LOESCH, C. Estatística e probabilidades. Rio de Janeiro, LTC, 2012.

MALHOTRA, N. K. Pesquisa de marketing. Porto Alegre: Bookman, 2001.

POLIT, D. F.; BECK, C. T.; HUNGLER, B. P. Fundamentos de pesquisa: métodos, avaliação e utilização. Porto Alegre: Artmed, 2004.

REIS, C. Z. T.; SILVEIRA, S. F. R.; FERREIRA, M. A. M. Autoavaliação em uma instituição federal de ensino superior: resultados e implicações. Revista Avaliação, Sorocaba, SP, v. 15, n. 3, p. 109-129, 2010.

UNIVERSIDADE FEDERAL DE SANTA MARIA. Comissão Própria de Avaliação. Relatório de avaliação interna: autoavaliação da UFSM 2016. Disponível em: $<$ http://coral.ufsm.br/avaliacaoufsm/images/documentos/relatorios/2016-2017.pdf $>$. Acesso em 07 jun. 2017. 